\title{
Quitting smoking: why, how, and what might help
}

\author{
Linda L Pederson, Shelley B Bull, Mary Jane Ashley, John K MacDonald
}

Department of Community Health and Preventive

Medicine, Morehouse

School of Medicine,

Atlanta, Georgia, USA

Drew-Meharry-

Morehouse

Consortium Cancer

Center

Ontario Tobacco

Research Unit,

Toronto, Ontario,

Canada

LL Pederson

Samuel Lunenfeld

Research Institute,

University of Toronto

and Ontario Tobacco

Research Unit

SB Bull

Preventive Medicine and Biostatistics,

University of Toronto and Ontario Tobacco Research Unit

MJ Ashley

Department of

Epidemiology and

Biostatistics,

University of Western

Ontario, London,

Ontario

JK MacDonald

Correspondence to: Dr LLL Pederson

Department of Community Health and Preventive Medicine, Morehouse School of Medicine, 720 Westview Drive, SW, Atlanta, Georgia 30310-1495, USA; email: lindap@mindspring.com.

\begin{abstract}
Objective-To examine reasons for quitting smoking, methods used in quitting, reasons for continuing smoking and potential aids to quitting in the population of Ontario, Canada.
\end{abstract}

Design-Two population-based, telephone interview surveys, conducted by randomdigit dialing.

Subjects-Adults aged 18 years of age and older in $1983 \quad(n=1383)$ and 1991 (n = 1421).

Main outcome measures-Information was obtained from former smokers on why and how they quit smoking, and from continuing smokers on why they smoked and what might help them quit.

Results-The proportion of current smokers in the population decreased from $35.5 \%$ in 1983 to $27.2 \%$ in 1991 . In both surveys, former smokers cited a variety of reasons for quitting, including personal health concerns, social and environmental factors, personal attitude factors, cost, and health education messages. Responses concerning the most important reason also revealed a range of factors; "advice of a physician" was not prominent among them. When questioned about methods used in quitting, most former smokers in both surveys responded that they "just decided to quit". Very few reported using other aids such as cessation clinics or nicotine gum. More smokers in 1991 than in 1983 reported that they continued smoking for enjoyment, to satisfy a craving or addiction, and for relaxation. With regard to what might help them quit, continuing smokers in both surveys cited a wide variety of potential aids, including information on harmful effects, more restrictions on smoking and on sales, cessation clinics, programmes on radio/ $T V$, and higher taxes.

Conclusions-These findings support a multifaceted approach to tobacco control.

(Tobacco Control 1996;5:209-214)

Keywords: smoking cessation; current smokers; former smokers

\section{Introduction}

In both the United States and Canada, there has been a substantial reduction in the prevalence of smoking in all age groups in the past 25 years. $^{1-9}$ Much of this reduction is accounted for by the large number of smokers who have quit. Most people who quit smoking do so on their own, without the aid of special programmes or treatments; it has been estimated that more than $80 \%$ of those who are successful quit without formalised treatment. ${ }^{10-12}$ However, relatively little information is available on how this process is accomplished, particularly information that might be useful in determining programming and policy interventions. In addition, information on continuing smokers' beliefs about what would help them quit is limited. The purpose of the secondary data analyses reported here is to provide population-based information on individuals who have quit smoking and on individuals who continue to smoke, and changes in both groups over time.

\section{WHO QUITS, HOW, AND WHY?}

In both large-scale interventions and population surveys, factors that have been consistently related to successful abstinence are: being male, being less dependent on nicotine, older age, having higher socioeconomic status or educational achievement, previous quit attempts, and health concerns or problems. ${ }^{13-20}$ Some individuals have reported use of nicotine replacement therapy ${ }^{1321}$ or physician advice ${ }^{22}$ but most individuals indicate they "just decided to quit" and did so on their own. ${ }^{10-12}$

Although the attributes of smokers that predict smoking cessation have been investigated, fewer investigations have focused on the relationships between the reasons stated for quitting and long-term abstinence. ${ }^{1214152324}$ After adjustment for sociodemographic variables, Gilpin et $a l^{15}$ found that health, social, and cost reasons were all related to successful cessation in a cross-sectional general population survey. Individuals who responded that they quit for both health and social reasons combined were the most likely to quit. Health concerns appear to motivate cessation. Derby et $a l^{4}$ found that successful cessation was associated with efforts to increase exercise in both women and men. In a study of nurses, Swenson and Dalton $^{23}$ found that health reasons were given most often by those nurses who had successfully quit smoking, followed by social reasons.

Halpern and Warner ${ }^{14}$ found that successful cessation was associated with having personal concerns about the health effects of smoking and with wanting to set a good example for children. Surprisingly, the cost of tobacco, the effect of smoking on the health of others, and pressure from family and friends to quit were not associated with likelihood of cessation in this study. In an analysis of the "1994 Smoking of Canadians Survey," Stephens and Stephens ${ }^{12}$ found that concern about present health was cited by older individuals, whereas the cost of tobacco was cited by those in 
younger age groups. Less than $5 \%$ of the quitters cited pregnancy, social pressure, and doctor's advice as motivation for quitting. The apparent inconsistency in the results of this latter study with those of Halpern and Warner ${ }^{14}$ is probably due, in part, to differences in taxation levels between the United States and Canada, with Canada having relatively higher taxes on cigarettes.

WHO CONTINUES TO SMOKE AND WHY?

A variety of constructs has been used to explain why people continue with a behaviour they know is harmful to their health and the health of those around them. ${ }^{2526}$ Among the explanations are those dealing with smoking as an addiction, a relaxant, a stimulant, and a strong habit with innumerable repetitions. Some individuals smoke to control their weight; weight gain following cessation has been well documented, although it is not clear whether this is the result of increased energy consumption, changes in metabolic rate, or both. ${ }^{26}$ Further, the importance of weight concerns as a determinant of continuing smoking at the population level is not clear. Indeed, in a recent population-based study, ${ }^{27}$ it was found that weight concerns and dieting efforts did not appear to inhibit smoking cessation or increase relapse in adults.

Many studies have examined factors related to continuing to smoke. Among the demographic characteristics found are lower socioeconomic status and, in some studies, being female. ${ }^{14} 1928$ With regard to smoking history, greater level of addiction or dependence has been consistently reported to be related to continued smoking. ${ }^{142}$ Among those factors considered to be psychosocial in nature, low self-efficacy, history of depression, low self-esteem, concern about weight gain, and less concern about health risks have all been found to be characteristic of continuing smokers. ${ }^{30-34}$ The relationships are consistent regardless of whether the studies were evaluations of interventions or populationbased surveys.

Relatively few studies have examined the relationships between the reasons given for smoking and continued smoking. Swenson and Dalton, ${ }^{23}$ in the study of nurses cited above, found that enjoyment and tension reduction were the most frequently reported reasons for continuing to smoke. Stephens and Stephens ${ }^{12}$ found that relaxation was the most frequently reported reason for resuming smoking after a quit attempt. Smoking to alleviate withdrawal and craving are often cited as reasons for continuing to smoke and are reported frequently in conjunction with failed quit attempts. ${ }^{35}$ Having other smokers in one's social network also appears to be related to continuing to smoke. ${ }^{12-13} 1733$ 35-37

\section{WHAT IS NEEDED?}

What has not been adequately addressed in the literature are questions concerning methods that continuing smokers perceive would be helpful to them in quitting. In addition, very little is known about how those individuals who have achieved and maintained abstinence have done so. Little is known about whether changes have occurred in the reasons for and methods of quitting in a context of decreasing social acceptability of smoking and increasing restrictions on where smoking is permitted.

In this paper we report findings from two population-based surveys in the province of Ontario, Canada. ${ }^{138}$ Despite some variation in the wording of one of the questions, it was possible to reach conclusions regarding why and how people quit smoking and why smokers continue to smoke, along with their suggestions concerning what would be helpful to them in quitting. Possible changes that may have occurred in these variables between 1983 and 1991 because of the increased restrictions on smoking in public places and workplaces, ${ }^{39}$ and the stronger social sanctions against smoking in general, were also of interest. ${ }^{40}$

\section{Methods}

Similar methods were used for both the 1983 and 1991 surveys, with one exception in the wording and presentation of the question concerning why individuals quit smoking (see tables 1 and 2). The design and methodology of the surveys have been described fully elsewhere. ${ }^{138}$ Briefly, a three-stage sampling design was used. The primary sampling units were census subdivisions, which were stratified for the level of municipal smoking restrictions in effect in 1983 and urban/rural residence. In the second sampling stage, the sampling units were households with active telephone numbers, selected using random-digit dialing. These households comprised $97 \%$ of the target population, ${ }^{41}{ }^{42}$ which was all residents of the province 18 years of age and older. The third and final stage involved the selection of one respondent within each household.

The data were collected during a 20-25-minute telephone interview that included questions about knowledge of health effects, attitudes toward a variety of restrictions on smoking, and sociodemographic information. For current and former smokers, items about smoking behaviour included were: reasons for and methods of quitting; reasons for smoking; and techniques used or potentially useful for quitting.

For the purposes of statistical analysis, the information was tabulated as percentages. Observations were weighted in these calculations according to the sample design. Ninety-five per cent confidence intervals were calculated in each survey using Fleiss' small-sample method, ${ }^{43}$ with adjustments for the complex sampling design. ${ }^{44}$ Nonoverlapping confidence intervals were considered to be evidence of significant changes between 1983 and 1991, which effectively tests at approximately $\mathrm{P}=0.005$. The SAS statistical package was used in the analyses.

Several of the items allowed for responses other than those specified. Responses to the "other" category were incorporated into 
Table 1 Reasons for quitting smoking reported by former smokers $\dagger$

\begin{tabular}{lcccc}
\hline Reason & $\begin{array}{l}1983(n=311) \\
\%\end{array}$ & $95 \% C I$ & $\begin{array}{l}1991(n=396) \\
\%\end{array}$ & $95 \% C I$ \\
\hline Personal health reason & & & & \\
$\quad$ Health problem & 37.2 & $28.5-40.5$ & 35.7 & $31.1-40.2$ \\
$\quad$ Physical fitness & 5.9 & $3.5-9.5$ & 46.6 & $41.0-52.4^{\star}$ \\
$\quad$ Advice of physician & 6.8 & $4.2-10.7$ & 14.0 & $10.5-18.4$ \\
$\quad$ Pregnancy & 6.8 & $4.0-11.3$ & 3.7 & $1.7-7.5$ \\
Social environment & & & & \\
$\quad$ Relatives encouraged & 11.6 & $8.3-16.0$ & 34.3 & $29.0-40.5^{\star}$ \\
$\quad$ Example for children & 5.7 & $3.5-8.9$ & 33.0 & $27.0-39.7^{\star}$ \\
$\quad$ Illness of friend & 3.6 & $2.1-6.0$ & 11.4 & $8.1-16.2^{\star}$ \\
Personal attitude & & & & \\
$\quad$ Test willpower & 4.7 & $2.2-9.4$ & 31.8 & $25.0-39.2^{\star}$ \\
$\quad$ No longer enjoy & 22.3 & $15.1-31.5$ & 10.8 & $7.7-15.4$ \\
Cost of tobacco & 12.7 & $9.0-18.2$ & 40.7 & $34.9-46.5^{\star}$ \\
Advertising about health effects & 9.5 & $6.2-14.3$ & 28.5 & $22.3-35.3^{\star}$ \\
Other & 6.3 & $3.7-10.4$ & 9.1 & $6.6-13.4$ \\
\hline
\end{tabular}

$\star$ Significant change, $\mathrm{P}<0.005$.

† 1983 Question: "Why did you quit smoking? Any other reasons?"; 1991 Question: "I am going to read you a list of reasons why people quit smoking. For each, please tell me if it was a reason why you quit smoking. Was there another reason you quit smoking?".

¥ For 1991 the "other" category includes: religious convictions, concerns over environmental tobacco smoke, and aesthetics.

$95 \% \mathrm{CI}=95 \%$ confidence interval.

Table 2 Most important reason for quitting smoking reported by former smokers $\dagger$

\begin{tabular}{|c|c|c|c|c|}
\hline Reason & $\begin{array}{l}1983(n=311) \\
\%\end{array}$ & $95 \% C I$ & $\begin{array}{l}1991 \quad(n=396) \\
\%\end{array}$ & $95 \% C I$ \\
\hline Personal health reason & 41.2 & $36.6-46.9$ & 38.8 & $33.4-44.3$ \\
\hline Health problem & 29.7 & $23.6-36.5$ & 22.8 & $17.8-28.6$ \\
\hline Physical fitness & 3.9 & $1.9-7.8$ & 11.3 & $7.8-16.0$ \\
\hline Advice of physician & 2.4 & $0.9-5.8$ & 0.9 & $0.2-3.2$ \\
\hline Pregnancy & 5.7 & $3.1-10.1$ & 3.8 & $1.9-7.1$ \\
\hline Social environment & 14.6 & $10.8-19.5$ & 20.1 & $16.0-24.9$ \\
\hline Relatives encouraged & 8.6 & $5.3-13.5$ & 8.7 & $5.7-13.1$ \\
\hline Example for children & 3.1 & $1.4-6.8$ & 6.6 & $4.0-10.6$ \\
\hline Illness of friend & 2.9 & $1.2-6.5$ & 4.8 & $2.6-8.4$ \\
\hline Personal attitude & 21.5 & $16.4-27.6$ & 17.6 & $13.2-23.0$ \\
\hline Test willpower & 2.8 & $1.2-6.4$ & 6.2 & $3.7-10.1$ \\
\hline No longer enjoy & 18.7 & $13.7-24.9$ & 11.4 & $7.9-16.1$ \\
\hline Cost of tobacco & 6.6 & $3.8-11.1$ & 8.8 & $5.7-13.1$ \\
\hline Advertising about health effects & 4.9 & $2.5-9.04$ & 5.6 & $3.3-9.4$ \\
\hline Other & 10.7 & $7.89-14.3$ & 9.2 & $7.0-12.0$ \\
\hline Other $\ddagger$ & 4.9 & $2.6-9.1$ & 8.7 & $5.7-13.0$ \\
\hline Don't know & 5.8 & $3.2-10.1$ & 0.5 & $0.1-2.7^{\star}$ \\
\hline
\end{tabular}

$\star$ Significant change, $\mathrm{P}<0.005$.

$\dagger 1983$ Question: If respondent gave more than one reason, ask: "Of these reasons that you mentioned, which was the most important?"; 1991 Question: If respondent gave more than one reason, read out list and ask: "Of these reasons that you mentioned, which was the most important?"

$\ddagger$ For 1991 the "other" category includes: religious convictions, concerns over environmental tobacco smoke, and aesthetics.

$95 \% \mathrm{CI}=95 \%$ confidence interval.

existing categories when possible; otherwise they were left as "other" in the analysis.

\section{Results}

There were 1383 and 1421 eligible respondents in the 1983 and 1991 surveys, respectively. The response rates, adjusted for distributions of potential respondents and ineligibles among the non-contacts, were $75 \%$ and $78 \%$ for the two years. Comparison of the 1991 survey respondents to those in 1983 showed no significant differences in the age-sex distribution. Consistent with changes in the provincial census populations, the 1991 respondents had higher levels of education and were more likely to have never married. Respondents in both surveys over-represented high school graduates. The finding of higher levels of education among survey participants has been reported by others. ${ }^{45}$

Overall, $42.0 \%$ of the 1983 sample and $44.8 \%$ of the 1991 sample reported never having smoked. Former smokers, abstinent for at least six months, comprised $21.3 \%$ and $24.7 \%$ of the 1983 and 1991 samples, respectively, and those abstinent for less than six months were $1.2 \%$ of the sample in 1983 and $3.2 \%$ in 1991 (total quitters in $1983=311$, in $1991=$ 396). The percentage of current smokers decreased from $35.5 \%$ to $27.2 \%$ between the two time periods. Former smokers and current smokers in the 1991 survey were similar to their counterparts in 1983, with respect to the distributions of age, sex, marital status, and education ( $\mathrm{n}=381$ current smokers in 1983, $\mathrm{n}=297$ in 1991).

\section{FORMER SMOKERS}

Table 1 presents the reasons for quitting smok- $\vec{C}$ ing given by former smokers in each survey. In or 1983, this question was asked as an open-ended one. In 1991, it was presented as a 8 closed (aided) question in which a response was required for each reason. As a result, individuals gave more reasons for quitting in $1991 \mathrm{C}$ than in 1983, and it is not possible to determine for the specific reasons whether the statistically significant increases between 1983 and 1991 reflect the different way in which the question was presented or true increases in the relevance of the reason to the quit-smoking decision. Nonetheless, in both surveys a variety of reasons were cited, including those related to: personal health concerns, social and environmental factors, personal attitudes, cost, and health education. Although personal health problems clearly predominated in the unaided responses obtained in 1983, the aided 1991 responses mentioned many more factors from several domains almost as often or more often. In both surveys, individuals who provided more than one response were asked to indicate their most important reason among the ones they had given. Their responses were tabulated with those individuals who provided only one reason (table 2). Personal health reasons, and specifically health problems, provided the greatest impetus for achieving abstinence in both surveys. A borderline statistically significant increase occurred in physical fitness as the most important reason for cessation. None of the other categories approached significance with the exception of the "don't know" response, which decreased over time.

When former smokers were asked how they N quit (table 3), the majority in both years $\mathrm{N}$

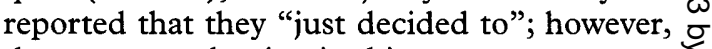
there was a reduction in this response category from 1983 to 1991 . A significant increase in $\frac{2}{\mathbb{D}}$ the "other" category, reflected some new tech- $\stackrel{0}{+}$ niques that became available in the intervening years. Other methods for quitting were infrequently mentioned in both surveys.

\section{CURRENT SMOKERS}

The proportion of current smokers who reported enjoyment, craving/addiction, and relaxation as reasons for smoking increased $\stackrel{\underline{\partial}}{\vec{P}}$ significantly between the two surveys (table 4). In 1991, these four reasons were cited by a clear majority of current smokers. Habit as a 
Table 3 Methods used for quitting reported by former smokers $\dagger$

\begin{tabular}{llccc}
\hline Methods & $\begin{array}{c}1983 \text { Estimates } \\
(n=311) \%\end{array}$ & $95 \% C I$ & $\begin{array}{l}1991 \text { Estimates } \\
(n=395) \%\end{array}$ & $95 \% C I$ \\
\hline Just decided & 93.9 & $89.9-96.4$ & 80.5 & $76.7-85.0^{\star}$ \\
Cessation clinic & 0.5 & $0.0-2.6$ & 2.8 & $1.5-5.1$ \\
Nicotine gum & 2.0 & $0.7-4.8$ & 1.9 & $0.8-4.1$ \\
Hypnotist & 0.6 & $0.1-2.3$ & 1.1 & $0.3-2.7$ \\
"How to" books & 0.0 & & 0.1 & $0.0-0.8$ \\
Other & 2.8 & $1.4-5.5$ & 13.3 & $10.2-16.5^{\star}$ \\
\hline
\end{tabular}

* Significant change, $\mathrm{P}<0.005$.

† 1983 and 1991 Question: "How did you quit smoking? Anything else?"

¥ For 1991 the "other" category includes: laser, computer, acupuncture, gradually reduced, religious conviction, smoking prevented by illness/health, social/peer support, and oral substitute.

$95 \% \mathrm{CI}=95 \%$ confidence interval.

Table 4 Reasons for smoking reported by current smokers $†$

\begin{tabular}{lllll}
\hline Reason & $\begin{array}{l}1983(n=490) \\
\%\end{array}$ & $95 \% C I$ & $\begin{array}{l}1991(n=387) \\
\%\end{array}$ & $95 \% C I$ \\
\hline Habit & 70.8 & $65.8-75.3$ & 81.5 & $75.2-86.5$ \\
Enjoy & 65.8 & $60.5-71.0$ & 79.0 & $73.6-83.4^{\star}$ \\
Craving/addiction & 43.8 & $38.1-49.7$ & 73.3 & $67.9-77.8^{\star}$ \\
Relaxation & 52.4 & $47.2-57.6$ & 72.4 & $67.1-77.0^{\star}$ \\
Weight & 18.0 & $14.6-22.0$ & 24.6 & $19.0-31.5$ \\
Peps me up & 7.4 & $5.7-9.6$ & 11.3 & $7.8-15.7$ \\
Otherł & 5.0 & $2.7-9.1$ & 21.1 & $16.5-27.4^{\star}$ \\
\hline
\end{tabular}

* Significant change, $P<0.005$.

$† 1983$ and 1991 Question: "I am going to read you a list of reasons that people give for smoking. For each one, please tell me if it is a reason for your smoking. Any other reason?"

$\ddagger$ For 1991 the "other" category includes: others also smoke, keep occupied, while drinking, and don't know.

$95 \% \mathrm{CI}=95 \%$ confidence interval.

Table 5 What would help you quit?: Current smokers who want to quit $\dagger$

\begin{tabular}{|c|c|c|c|c|}
\hline Method & $\begin{array}{l}1983(n=381) \\
\%\end{array}$ & $95 \% C I$ & $\begin{array}{l}1991(n=297) \\
\%\end{array}$ & $95 \% C I$ \\
\hline \multicolumn{5}{|l|}{ Health concerns } \\
\hline $\begin{array}{l}\text { Information about harmful } \\
\text { effects }\end{array}$ & 37.8 & $30.9-45.2$ & 33.8 & $27.8-40.0$ \\
\hline \multicolumn{5}{|l|}{ Legislative } \\
\hline Restrictions on smoking & 29.6 & $25.0-34.7$ & 27.9 & $22.4-34.3$ \\
\hline Restrictions on sales & 22.4 & $17.2-28.7$ & 22.5 & $16.7-29.1$ \\
\hline Less advertising & 15.5 & $11.8-20.1$ & 9.8 & $6.4-14.5$ \\
\hline Higher taxes & 12.3 & $9.3-16.1$ & 18.6 & $13.0-25.5$ \\
\hline \multicolumn{5}{|l|}{ Cessation aids } \\
\hline Cessation clinic & 21.1 & $17.0-25.8$ & 21.8 & $16.7-28.3$ \\
\hline Self-help books & 13.0 & $9.8-17.0$ & 11.8 & $7.0-17.6$ \\
\hline Programme on radio/TV & 21.5 & $17.2-26.5$ & 19.2 & $13.9-24.3$ \\
\hline Other $\ddagger$ & 3.4 & $1.9-5.6$ & 50.2 & $39.6-54.9^{\star}$ \\
\hline
\end{tabular}

* Significant change, $P<0.005$.

+1983 and 1991 question: "I am going to read you a list of ways that have helped people quit smoking. For each one, tell me if you think it would help you quit. Anything else you can think of?"

$\ddagger$ For 1991 the "other" category includes: will power, medical problems/pregnancy, others also quit, relief of stress, acupuncture, hypnosis, laser, and Nicorette. $95 \% \mathrm{CI}=95 \%$ confidence interval.

reason also appeared to increase, with only a slight overlap in the confidence intervals. The percentage of individuals who claimed that smoking prevents weight gain and "peps me up" increased in 1991 compared with 1983, but these changes were not statistically significant. There was a significant increase in the "other" category, which included answers such as "others also smoke", "to keep busy", "while drinking", and "don't know".

Among the current smokers who want to quit (approximately $75 \%$ in each survey), information on harmful effects, legislative measures including restrictions on smoking and sales, and cessation clinics were the most frequently mentioned as being possible aids for quitting smoking (table 5). With the exception of the "other" category, which in 1991 included a wide variety of techniques such as willpower, medical problems, others also quit, relief of stress, acupuncture, hypnosis, laser, and nicotine gum, there were no differences between 1983 and 1991 in reports of current smokers about what would help them quit.

\section{Discussion}

These findings should be interpreted with caution. Because the samples as a whole were not completely representative, bias is possible. ${ }^{138} \mathrm{~A}$ comparison with provincial census data revealed differences in the sex ratio in some age categories and in certain educational and occupational groups. Although it is possible that these differences could have biased some of the findings, this would only be the case if non-responding current or former smokers gave different reasons for their behaviour than those who did participate in the survey. In addition, our study did not include objective validation of smoking status and, consequently, misrepresentation of status may have occurred; this may be more of an issue in the 1991 survey than the 1983 survey because of the increasing social unacceptability of smoking. The consequences of misrepresentation would likely be more misclassification of current smokers as former smokers in the second survey. If this were the case, it is not clear whether the differences would have been even greater or whether the same magnitude of differences would have been found.

Among the reasons provided by those who quit smoking, concern for personal health was one of the major motivators for cessation in 1983 and 1991, regardless of the format of the question. Thus it is noteworthy that "advice of a physician" was not prominent among the reasons for quitting, even in the aided 1991 question. However, in randomised controlled trials, physician advice has been shown to be effective in increasing cessation in patients seen in family practice and other healthcare settings. ${ }^{4647}$ Programmes designed to increase the effectiveness of physicians and other health professionals with regard to smoking cessation have now been implemented and are being evaluated..$^{48} 49$

The responses to the 1991 aided questions indicate that many factors may contribute to individual decisions to quit smoking. Besides personal health problems, concerns about physical fitness, encouragement from relatives, setting an example for children, and cost of tobacco were all cited by a third or more of respondents. Responses concerning the most important factor for quitting also indicate that a range of factors are involved. The multifaceted approach to tobacco control that has characterised the combined efforts of government, the voluntary health associations, and non-smokers' rights groups during the 1980 s is consistent with such a multifactorial model of smoking cessation on a population basis. With regards to the strategies former smokers say they use to quit, it is noteworthy that most say they "just decided to quit" and did so. In all likelihood, this is a simplification of the process, as media messages, health effects, social unacceptability, and other factors probably play some role in the decision. What 
exactly is involved in reaching this decision is an important subject for future research in this area, particularly in qualitative studies. Even in 1991, few quitters report using cessation clinics or other aids such as Nicorette gum. In the future, research efforts focusing on the underlying mechanisms for progression through the "stages of change" 50 may provide insight into intervention approaches that would facilitate cessation, along with investigations aimed at improving the effectiveness of already existing cessation aids.

Although it is encouraging that the proportion of current smokers has decreased between the two time periods, our results suggest that the 1991 group of smokers was quite different than their 1983 counterparts. In 1991, current smokers were much more likely to report craving as a reason for smoking, and they continue to smoke despite the overwhelming and continually growing evidence on the detrimental health effects of active and passive smoking. Hence, it is not unreasonable to conclude that, as a group, they may have been more addicted than smokers in the early 1980s. Further, this suggests that a sizable proportion of people who try to quit in the 1990 s may experience more difficulty quitting than those who made these attempts in the $1980 \mathrm{~s},{ }^{5152}$ implying that other methods besides "just doing it" will be needed. In addition, a sizable percentage reported weight concerns as a reason for continuing to smoke, suggesting that at least for some smokers, strategies to control weight gain should be incorporated into cessation programming.

The potential importance of legislative measures in cessation can be found in the responses of current smokers. Frequently cited reasons for or aids to quitting were legislated measures: restrictions on smoking in public places, restrictions on sales, less advertising, and higher taxes. In addition, other findings from these two provincial surveys, ${ }^{1534}$ reveal that both smokers and non-smokers support such regulation of smoking, providing a strong basis for restrictive interventions. Although support for legislative measures is stronger among non-smokers than among smokers, the growing support among smokers provides ample justification for the continuation of such efforts.

In conclusion, the findings strongly suggest the continuing need for multifaceted tobacco control programmes. Educational efforts should be accompanied by a deterrent taxation policy, other restrictive measures, and preventive and cessation services.

1 Bull SB, Pederson LL, Ashley MJ. Restrictions on smoking: growth in population support between 1983 and 1991 in Ontario, Canada. F Public Health Policy 1994;15:310-28.

2 Maxwell CJ, Hirdes JP. The prevalence of smoking and implications for quality of life among the communitybased elderly. Am f Prev Med 1993;9:338-45.

3 Millar WJ, Stephens T. Social status and health risks in Canadian adults: 1985 and 1991. Health Rep 1993;5:14356.

4 Brancker A. Lung cancer and smoking prevalence in Canada. Health Rep 1990;2:67-83.
5 US Centers for Disease Control. Smoking cessation during previous year among adults-United States, 1990 and 1991. MMWR 1993;42:504-7.

6 US Centers for Disease Control. Cigarette smoking among adults-United States, 1991. MMWR 1993;42:230-3.

7 US Centers for Disease Control. Cigarette smoking amon adults-United States, 1993. MMWR 1994;43:925-30.

8 US Centers for Disease Control and Prevention. Cigarette smoking among adults-United States, 1992, and change in the definition of current cigarette smoking. MMWR 1994;43:342-6.

9 Giovino GA, Schooley MW, Zhu BP, et al. Surveillance fo selected tobacco-use behaviors-United States, 1900 1994. $M M W R$ 1994;43(SS-3): 1-43.

10 Fiore MC, Novotny TE, Pierce JP, et al. Methods used to quit smoking in the United States: Do cessation program help? FAMA 1990;263:2760-65.

11 Pederson LL. Smoking behaviour of Canadians. In: Healt Promotion Survey 1990. Technical Report, Chapter 7. Ottawa: Health and Welfare Canada, 1992

12 Stephens T, Stephens C. Lapsed quitters and successfu quitters: Profiles of smokers in a national survey. Society of Behavioral Medicine Conference, San Diego, California, USA, March 1995.

13 Carmody TP. Preventing relapse in the treatment of nicotine addiction: current issues and future directions. $f$ Psychoactive Drugs 1992;24:131-58.

14 Halpern MT, Warner KE. Motivations for smokin cessation: a comparison of successful quitters and failures. ¥ Subst Abuse 1993;5:247-56.

15 Gilpin E, Pierce JP, Goodman J, Burns D, Shopland D. Reasons smokers give for stopping smoking: do they relate to success in stopping? Tobacco Control 1992;1:256-63.

16 Kaplan RM. Stages of smoking cessation: the 1990 California tobacco survey. Tobacco Control 1993;2:139-44.

17 Schoenbach VJ, Orleans CT, Wagner EH, Quade D, Salmo MA, Porter CQ. Characteristics of smokers who enrol and quit in self-help programs. Health Educ Res 1992;7:369 80

18 Hellman R, Cummings KM, Hanghey BP, Zielezny MA O'Shea RM. Predictors of attempting and succeeding at smoking cessation. Health Educ Res 1991;6:77-86.

19 Lundberg O, Rosen B, Rosen $M$. Who stopped smoking? Results from a panel survey of living conditions in Sweden. Soc Sci Med 1991;32:619-22.

20 Rohren CL, Croghan IT, Hurt RD, Offord KP, Marusic Z McClain Fl. Predicting smoking cessation outcome in medical centre from stage of readiness: contemplation versus action. Prev Med 1994;23:335-44.

21 Carmody TP. Affect regulation, nicotine addiction, and smoking cessation. F Psychoactive Drugs 1992;24:111-22.

22 US Centers for Disease Control. Public health focus: tiveness of smoking-control strategies. $¥ A M A 1992$ 268: $1645-6$.

23 Swenson I, Dalton JA. Reasons for smoking cessation among a random sample of North Carolina nurses. Woman Health 1983;8:33-41.

24 Derby CA, Lasater TM, Vass K, Gonzalez S, Carleton RA Characteristics of smokers who attempt to quit and of those who recently succeeded. Am fF Prev Med 1994 10:327-34.

25 Fisher EB, Lichtenstein E, Haire-Joshu D. Multiple determinants of tobacco use and cessation. In: Orleans CT, Slade J, eds. Nicotine addiction. Principles and management. New York: Oxford University Press, 1993:59-88.

26 Gilbert DG. Smoking: individual differences, psychopathology and emotion. Washington, DC: Taylor \& Francis, 1995.

27 French S, Jeffery R, Klesges L, Forster J. Weight concerns and change in smoking behavior over 2 years in a working population. Am F Public Health 1995;85:720-6.

28 Blake SM, Klepp KI, Pechacek TF, et al. Differences in smoking cessation strategies between men and women. Addict Behav 1989;14:409-18.

29 Richmond RL, Makinson RJ, Kehoe LA, Giugni AA, Webster IW. One-year evaluation of three smoking cessation interventions administered by general practitioners. Addict Behav 1993;18:187-99.

30 Owen N, Wakefield M, Roberts L, Esterman A. Stages of readiness to quit smoking: population prevalence and correlates. Health Psychol 1992;11:413-17.

31 Ahijevych K, Wewers ME. Processes of change across five stages of smoking cessation. Addict Behav 1992;17:17-25.

32 Haaga DA. Issues in relating self-efficacy to smoking relapse: importance of an achilles heel situation and of prior quitting experience 7 Subst Abuse 1990;2:191-200.

33 Haire-Joshu D, Morgan G, Fisher EB Jr. Determinants of cigarette smoking. Clin Chest Med 1991;12:711-25.

34 Sutton S, Marsh A, Matheson J. Explaining smokers' decision to stop: test of an expectancy value approach. Soc Behav 1987;2:35-49.

35 Lennox AS, Taylor RJ. Factors associated with outcome in unaided smoking cessation, and a comparison of those who have never tried to stop with those who have. $\mathrm{Br}$ f Gen Pract 1994;44:245-50.

36 Tunstall CD, Ginsberg D, Hall SH. Quitting smoking. Int $\mathcal{F}$ Addict 1985;20:1089-112

37 Unland $\mathrm{H}$. Is success in smoking cessation treatment prdictable? In: Zapotoczky $\mathrm{H}$, Wenzel $\mathrm{T}$, eds. The scientific dialogue: from basic research to clinical intervention scientific dialogue: from basic research to clinical inter

38 Pederson LL, Bull SB, Ashley MJ, Lefcoe NM. A population survey on legislative measures to restrict smoking in Ontario: 1. Design, methodology, and sample representativeness. Am F Prev Med 1986;2:307-15. 
39 Stephens T, Mitchell B. Reducing ETS exposure in public places frequented by children A discussion paper places frequented by children. A discussion paper shop to Reduce ETS Exposure. October 19-20, 1995. shop to Reduce ETS Exposure. October 19-20, 1995.
Ottawa. Minister of Supply and Services, Canada, 1996 (H39-370/2-1996E)

40 Pederson LL, Bull SB, Ashley MJ. Smoking in the workplace: do smoking patterns and attitudes reflect the legislative environment? Tobacco Control 1996;5:39-45.

41 Statistics Canada. Household facilities and equipment 1981. Ontario: Statistics Canada.

42 Ontario Telephone Service Commission. Annual Report, 1980. Ontari: Ontario Telephone Service Commission.

43 Fleiss JL Statistical methods for rates and proportions. 2nd ed. New York: John Wiley, 1981.

44 Cochran, WG. Sampling techniques. 3rd ed. New York: John Wiley, 1977.

45 Groves RM, Lyber LE An overview of nonresponse issues in telephone surveys. In: Groves RM, Biement PP, Lyberg $\mathrm{LE}$, et al. eds. Telephone survey methodology. New York: John 988:191-211.

46 Ockene JK Kristweller J, Pbert L, et al. The physiciandelivered smoking intervention project: Can short-term interventions produce long-term effects for a general outpatient population. Health Psych 1994;13:278-81.

47 Kottke TE, Battista RN, DeFriese Gh, Brekke ML Attributes of successful smoking cessation intervention in medical practice: A meta-analysis of 39 controlled trials. fAMA 1988;259:2882-9.
48 Coambs RB, Wilson E, Pederson LL. An evaluation of a dissemination study to train physicians to help patients with smoking cessation. In. $\mathrm{K}$ Slama, ed. Tobacco and health. Proceedings of the ninth world conference on tobacco and health, Paris, France, 10-14 October 1994. New York: Plenum Press, 1995:759-64.

49 Glynn TJ, Manley MM, Pechacek, TF. The physicianinitiated smoking cessation program: The NCI Trials. In Engstom PF, Rimer B, Mortenson LE, eds, Advances in cancer control. screening and prevention research. New York. Wily-Liss 1990;11-25.

50 Prochaska JO, Velicer WF, DiClemente CC, Guadagnoli E, Rossi JS. Patterns of change: Dynamic typology applied to smoking cessation. Multivar Behav Res 1991;26:83-107.

51 Giovino GA. Tobacco control and nicotine dependence. Tobacco Control 1996;5:1-4.

52 Coambs RB, Kozlowski LT, Ferrence RG. The future of tobacco use and smoking research. In: Ney T, Gale A, eds. Smoking and human behaviour, Chichester: John Wiley, 1989:337-48.

53 Ashley MJ, Bull SB, Pederson LL. Support among smokers and nonsmokers for restrictions on smoking. Am 7 Prev Med 1995;11:283-97.

54 Pederson LL, Bull SB, Ashley MJ, Lefcoe NM. A population survey in Ontario regarding restrictive measures on smoking: relationship of smoking status to knowledge, attitudes and predicted behavior. Int 7 Epidemiol 1987;16:383-91 carried three pictures of actors smoking, either in or outside movies: Sean Penn (bottom right), in an article entitled 'Who's the best actor in Hollywood?'; Brad Pitt (top right), who plays the assistant district attorney in Sleepers; and Denzel Washington (left), with Delroy Lindo in Malcolm X.
Smokes in the movies. The October 1996 isue of Movieline magazine
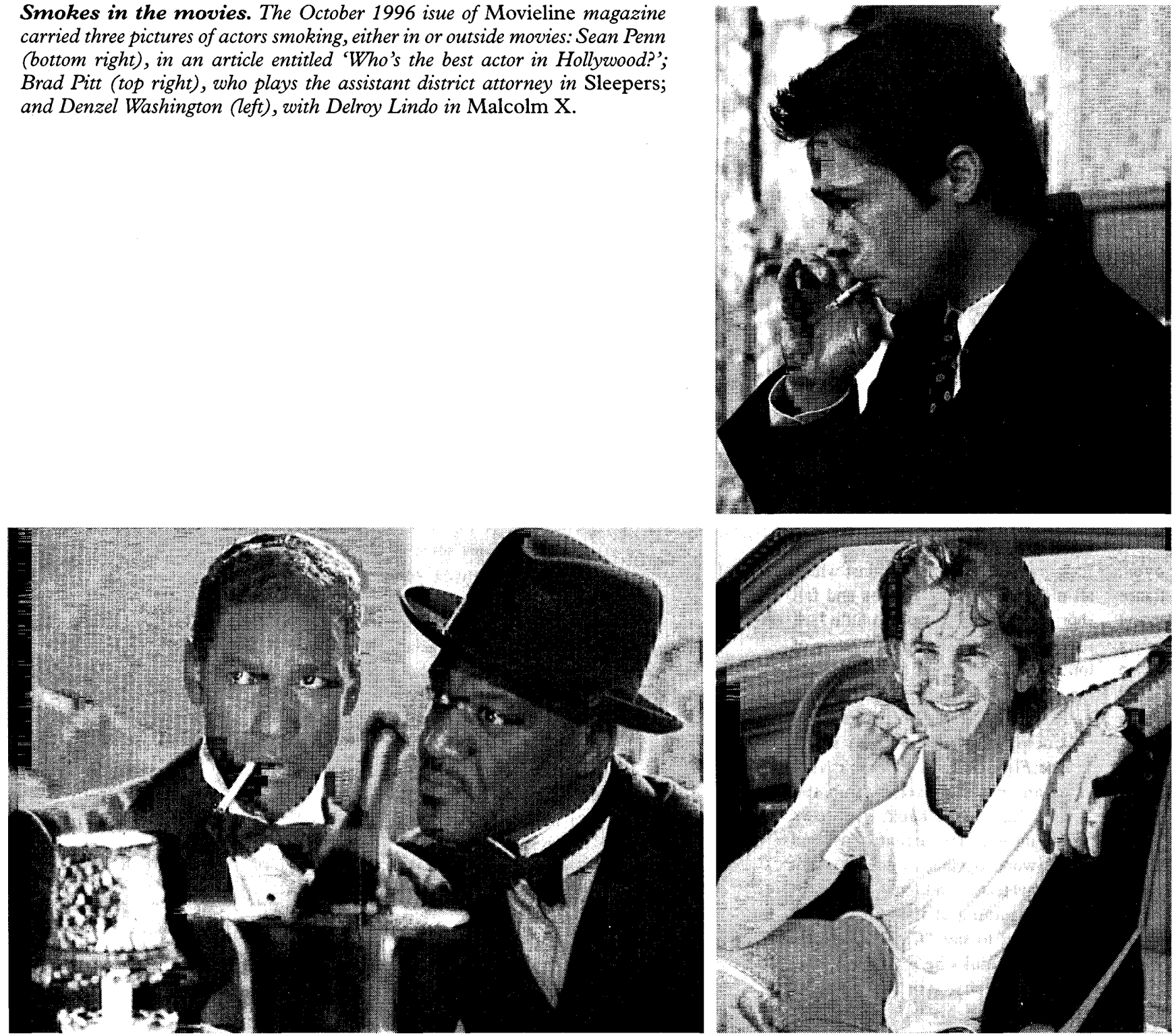

$$
\text { . }
$$$$
\text { . }
$$$$
\therefore
$$$$
-\infty
$$$$
-
$$$$
7
$$$$
x
$$$$
\rightarrow
$$$$
\therefore \rightarrow
$$$$
\text { a o }
$$$$
\vec{A}=\overrightarrow{0}
$$$$
\text { - } \overrightarrow{\vec{\omega}}
$$$$
\text { 7- }
$$$$
\therefore \rightarrow
$$$$
\therefore \quad \dot{c}
$$$$
\text { -i }
$$$$
\text { * 음 }
$$$$
\therefore \vec{\sigma}
$$$$
\text { WS } \frac{\mathbb{D}}{\mathrm{D}}
$$$$
\therefore \quad \frac{\pi}{0}
$$$$
+
$$$$
+\quad
$$$$
\text { i. }
$$$$
\text { a- }
$$$$
\text { Ax }
$$$$
\therefore
$$$$
\text { a }
$$$$
4
$$$$
\text { Ni }
$$$$
\Rightarrow \text { r }
$$$$
2
$$$$
\Delta
$$$$
\text { - }
$$$$
+4
$$$$
r \text {. }
$$$$
+\therefore
$$$$
\text { : 윽 }
$$$$
\text { \& }
$$$$
\text { 눙 }
$$$$
\text { int }
$$$$
\text { N }
$$$$
4=\quad \omega
$$$$
\therefore=\text { 定 }
$$$$
\therefore=\frac{0}{\frac{1}{D}}
$$$$
\text { ह- }
$$$$
\square \quad \frac{0}{0}
$$$$
7 \quad \frac{0}{1}
$$$$
4=\frac{O}{10}
$$$$
\text { - O }
$$$$
+2
$$$$
-1 \quad
$$$$
\text { : }
$$$$
+\cdots
$$ 